\title{
Effect of Nonuniform Partial Shading on the Performance of Photovoltaic Systems
}

\author{
Nabil Talbi, Toufik Sebbagh ${ }^{*}$, Abderrezak Metatla \\ LGMM Laboratory, University of 20 Août1955 - Skikda, ALGERIA \\ *e-mail: t.sebbagh@univ-skikda.dz
}

\section{SUMMARY}

This paper deals with the influence of the shading problem on the electrical production of a photovoltaic generator based on the analysis of the I-V and P-V characteristics of the PV generator for different operating scenarios. The shading problem not only causes energy losses but also increases the non-linearity of the I-V and P-V characteristics of photovoltaic systems. The choice of the model is an essential step to allow analysis and evaluation of the performance of photovoltaic generators. The single diode model was presented in the MATLAB / SIMULINK software. The study began with the presentation of the characteristics of a module, a comparison was made between the values of the obtained electrical parameters and those supplied by the manufacturer. To show the effect of shading on photovoltaic systems another comparative study was presented between a group of series-connected modules and another connected in parallel, both exposed to nonuniform partial shading. The obtained simulation results show that the influence of shading on a set of modules connected in series is greater than that of a set of modules connected in parallel under the same operating conditions.

KEY WORDS: $\quad$ PV systems; partial shading; bypass diode; series-connected; parallel-connected.

\section{INTRODUCTION}

Solar energy is freely available and abundant in most parts of the world. It is recognized as an economic source of energy when applied to several applications. It is an inexhaustible and pollution-free energy resource that plays a remarkable role in providing energy services in a sustainable way [1].

Photovoltaic (PV) systems directly convert the energy of the sun to electric energy [2]. PV arrays consist of several cells connected to provide the required voltage and current rating. PV generator can supply maximum power to the load at its maximum power point (MPP). The locus of this MPP varies non-linearly with the variation of irradiance and cell temperature [3].

A shadow is a three-dimensional zone of relative darkness formed when the passage of light is blocked by an opaque object [4]. Partial shading of PV panels can be caused by snow, clouds, trees and leaves, pollen, dirt, and dust. The effectiveness of PV panels is highly affected by 
shading, and their characteristics get complex with multiple peaks [5]. In this context, the authors of [6] carried out a systematic study of the shading effect on the power output, the fill factor, and the efficiency of a solar panel. They found a direct correlation between short circuit current and the irradiation intensity when the panel was uniformly shaded. However, the nonuniform shading yielded a variety of performance behaviour. The research published in [7] analysed the effect of shading on the energy production of a PV generator installed on a building roof. Two cases have been studied: in the first case the generator was originated by its tilted strings to determine their optimum tilt angle concerning both energy production and total surface, and in the second, it was projected by an adjacent tower building to evaluate production trend vs. the distance and the height of the obstacle. Authors in [8] worked on the experimental validation of the effect of partial shading on a PV power generating module by considering the change in current-voltage characteristics. The results of this study showed that the power loss occurred after shading one cell, one horizontal line, and one vertical branch. The authors of [9] performed a simulation study to illustrate the effect of partial shade on a PV array composed of two parallel strings, each consisting of 3 series-connected modules. Another research, [10], compared the effects of partial shading and dust accumulation on a PV module at different irradiation levels. The results show that among all the considered shading patterns and dust samples, diagonal partial shading patterns and ash dust samples have the most important effect on the performance of the PV module. Torres et al. [11] presented modelling and simulation of solar cells using PSPICE software and validated the results by comparison with the experimental results. In that study, the effects of temperature and partial shading on the performance of some PV modules were analysed. In [12], the authors conducted another research dealing with the modelling, simulation, and validation of the effect of shading on PV systems. A simple method based on five statements is presented in [13] to analyse the partial shading effects of a series-parallel connected PV array by the investigation of the I-V curves. A study presented by [14] dealt with the shadowing analysis of inclined and vertical poles and collectors, then used the obtained information for optimal deployment of a collector in a given area.

The current paper deals with the study of the effect of partial shading on the I-V and P-V characteristics of two PV arrays, each composed of three modules: the first is series-connected, and the second is parallel-connected. Matlab / Simulink software is used to simulate the partial shading on the two connection modes of PV modules. The most important contribution is that the simulation is carried out considering the nonuniform distribution of the partial shading of the modules since the partial shading can arbitrarily be found anywhere on the array. In this context, the research is performed within five scenarios.

The remainder of this paper is organized as follows: Section two deals with the mathematical modelling of PV systems in both normal and distinct operating conditions. Section three describes the behaviour of PV systems under partial shading conditions. The fourth section illustrates the materials used and the methods followed when processing this research. The results and discussions are illustrated in section five. Finally, the paper is closed with a conclusion in section six. 


\section{MATHEMATICAL MODELLING OF PV SYSTEMS}

\section{A. MODELLING OF PV CELL UNDER NORMAL CONDITIONS}

The generalized model known as the one diode/two resistors model, illustrated in Figure 1, is used in the current study. The mathematical model that represents the current output can be derived as in Eq. (1):

$$
I=I_{P h}-I_{0} e^{\left(\frac{V+I R_{S}}{a V_{T}}\right)-1}-\frac{V+I R_{S}}{R_{S h}}
$$

Where $I_{P h}$, is the photocurrent; $I_{0}$ is the reverse saturation current; $V_{T}$ is the thermal voltage; $a$ is the ideality factor; $R_{S}$ and $R_{s h}$ are series and shunt resistors, respectively.

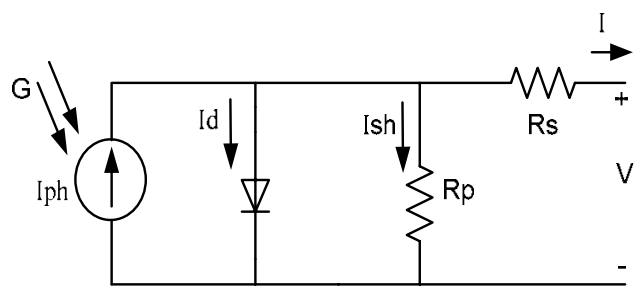

Fig. 1 Circuital diagram of one diode / 2 resistors solar cell

\section{B. MODELLING OF PV CELL UNDER DISTINCT OPERATING CONDITIONS}

Since PV cells are highly sensitive to the change of solar irradiance, it is important to analyse the effect of partial shade.

The model proposed in Eq. (1) did not consider the effect of shading. However, Bishop [15] proposed a mathematical model suitable for modelling solar cells in both normal and distinct conditions, expressed in Eq. (2). The circuital diagram is presented in Figure 2.

$$
I=I_{C C}-I_{01} *\left(\exp ^{\left(\mathrm{q} * \frac{\mathrm{v}+\mathrm{RS} * \mathrm{I}}{\mathrm{n} * \mathrm{~K} * \mathrm{~T}}\right)}-1\right)-\frac{V+R_{S} * I}{R_{S h}}\left(1+\left(\frac{a}{1-\frac{V+R_{S}^{* 1}}{V_{b r}}}\right)^{-m}\right)
$$

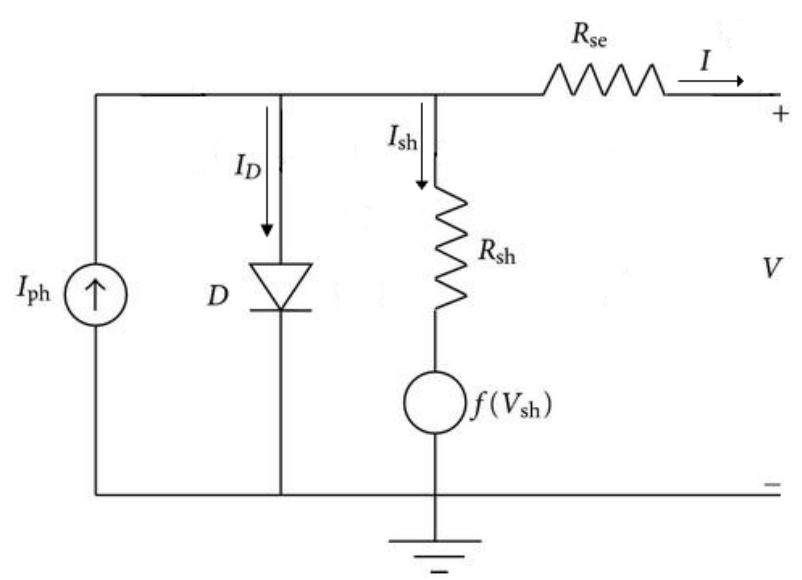

Fig. 2 Bishop's circuital diagram of PV cells 


\section{MATHEMATICAL MODELLING OF PV MODULES}

A PV module can be defined as a collection of cells assembled to generate a usable current and/or voltage when exposed to light. One single diode generates between 0.5 and 1.5 volts, depending on technology [16]. Almost several cells must be connected in series to generate a useful voltage. Therefore, the output voltage of a module depends on the voltage across the cell and the number of cells must be connected in series. This is formulated as in Eq. (3):

$$
V_{m}=N_{s} * V
$$

In Equation (3), $V_{m}$ is the module output voltage; $N_{s}$ is the number of series-connected cells.

\section{MATHEMATICAL MODELLING OF PV ARRAY}

An array is composed of the connection of several modules. An array composed of seriesconnected modules (Figure 3) is used to generate a higher voltage at a given current since the voltage generated is the sum of the output voltages of all modules. The array output voltage is formulated by Eq. (4) as:

$$
V_{\text {array }}=V_{m} * N_{s-m}
$$

Where: $V_{\text {array }}$ is the output voltage of the array; $N_{s-m}$ is the number of series-connected modules.

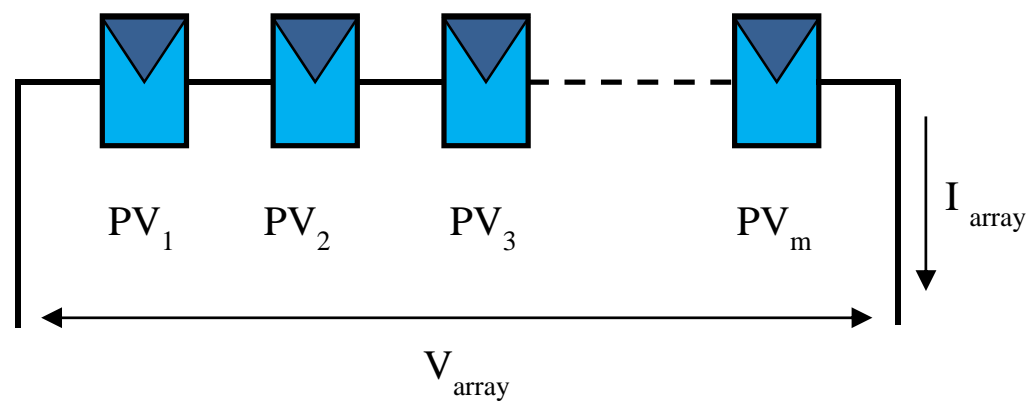

Fig. 3 Series-connected PV modules

On the other hand, an array composed of the parallel connection of a set of modules (Figure 4) is used to generate a higher current. In this case, the array output current is the sum of the output currents of the modules. This current is calculated by Eq. (5) as:

$$
I_{\text {array }}=I_{m} * N_{P-m}
$$

Where: $I_{\text {array }}$ is the current delivered by the array, $N_{P-m}$ is the number of shunt-connected modules.

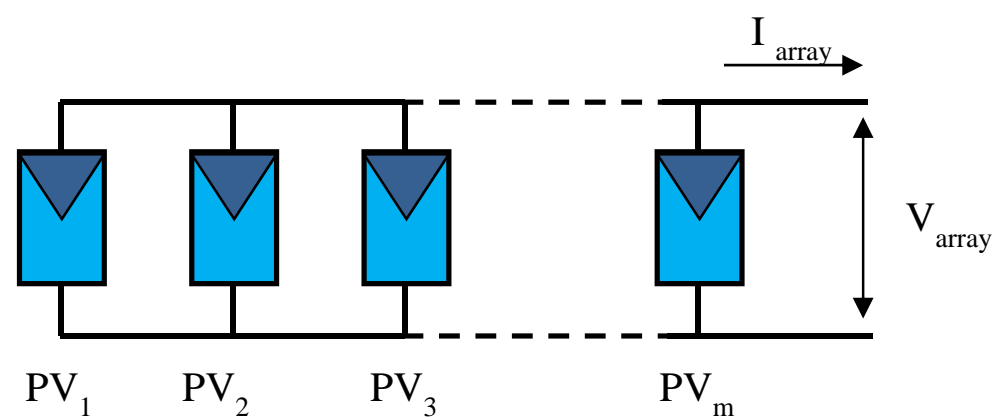

Fig. 4 Parallel-connection of PV modules 


\section{PV SYSTEM UNDER SHADING CONDITIONS}

The efficiency of PV systems is effectively influenced by irradiation. One realistic presentation of the partial shading phenomena is shown in Figure 5. The figure shows an arrangement of a PV array composed of 3 series-connected modules. In addition, a blocking diode is connected in series to prevent reverse currents from flowing back to the module. Furthermore, each module is associated with a bypass diode, connected in parallel and charged to protect the module from becoming a hot spot if the module is partially shaded [17].
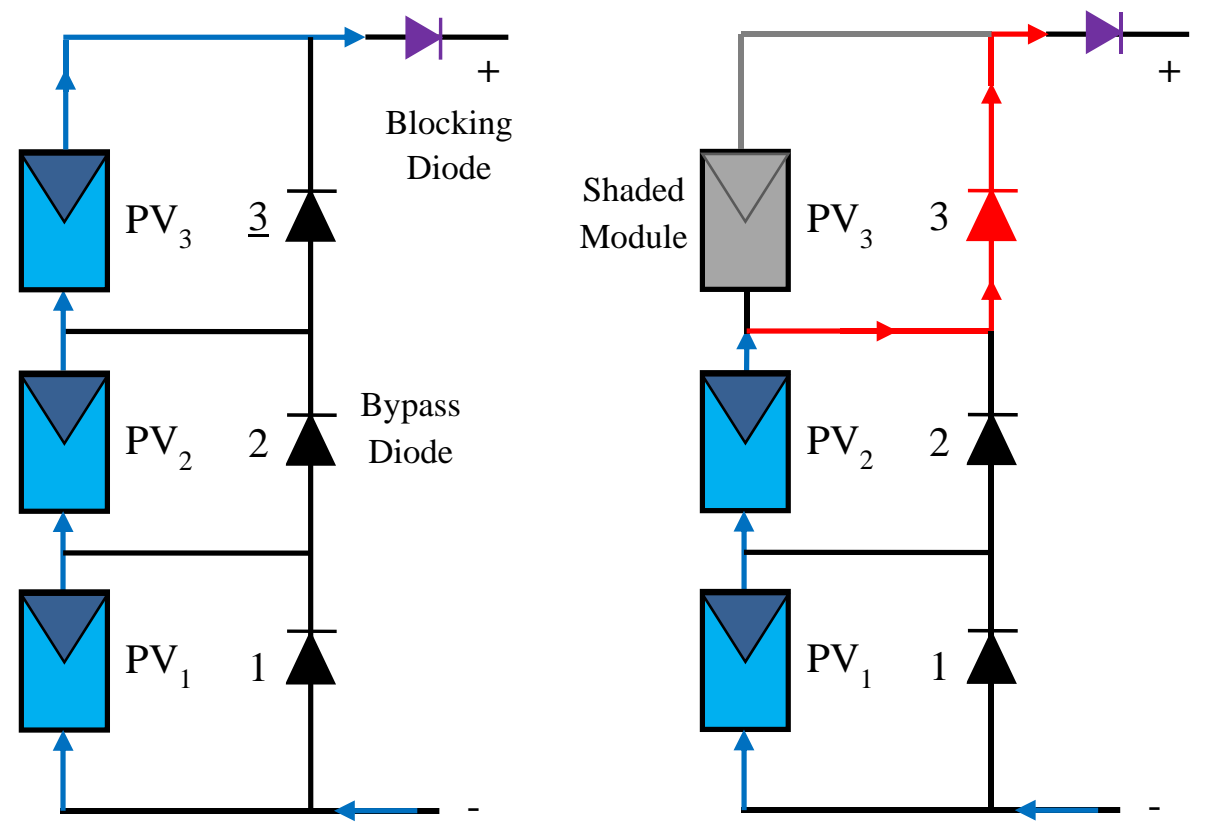

Fig. 5 Working principle of PV array: (a) under uniform irradiation, (b) under partial shading

Under uniform insolation, the bypass diodes are reverse biased, and the current flows through each module, as depicted in Figure 5(a). Under partial shading conditions, the shaded cells of the module become a load instead of a generator and create the hot spot problem. The hot spot effect can be avoided by driving the current away from the nonshaded cells through a bypass diode, as illustrated in Figure 5(b). In the shaded area, the bypass diode is forward biased, therefore, it conducts the current produced by the non-shaded part.

\section{MATERIALS AND METHODS}

The systems under study are simulated using the Matlab/Simulink software. The characteristics of the used PV system are shown in Table 1.

The steps followed during the simulation work are as follows:

- Validation of the one diode/two resistor model of the PV cell

- Implementation and verification of the Electric performances of the module presented in Table 1.

- Illustration of the effect of the series and parallel connections of the modules under study on the electric parameters of the array.

- Illustration of the impact of different ratios of partial shading on the IV and PV characteristics of different configurations. 
Table 1 Electric performance of Studied PV panel under STC* [18]

\begin{tabular}{|c|c|}
\hline Parameters & Values \\
\hline Maximum Power $\left(P_{\max }\right)$ & $200 \mathrm{~W}$ \\
\hline Maximum Power Voltage $\left(V_{\text {mpp }}\right)$ & $26.3 \mathrm{~V}$ \\
\hline Maximum Power Current $\left(I_{\text {mpp }}\right)$ & $7.61 \mathrm{~A}$ \\
\hline Open Circuit Voltage $\left(V_{O C}\right)$ & $32.9 \mathrm{~V}$ \\
\hline Short Circuit Current $\left(I_{S C}\right)$ & $6.62 \mathrm{~A}$ \\
\hline${ }^{*}$ STC (Standard Test Conditions): irradiance $100 \mathrm{~W} / \mathrm{m}^{2} ; \mathrm{AM} 1.5$ \\
Spectrum; module temperature $25^{\circ} \mathrm{C}$
\end{tabular}

\section{RESULTS AND DISCUSSIONS}

The simulation of one PV cell is done using Matlab/Simulink software. The model is designed based on the one diode/two resistor equivalent circuit. In the developed model, irradiance and temperature values have been inserted as input data using PV cell equations.

The I-V curve of the cell at STC conditions is shown in Figure 6(a), and the I-V characteristic of one module composed of 54 cells connected in series is shown in Figure 6(b). Figure 6 shows that the short circuit current of the module is equal to the short circuit current delivered by one cell. However, the open-circuit voltage of the module is the sum of the open-circuit voltages of all cells.

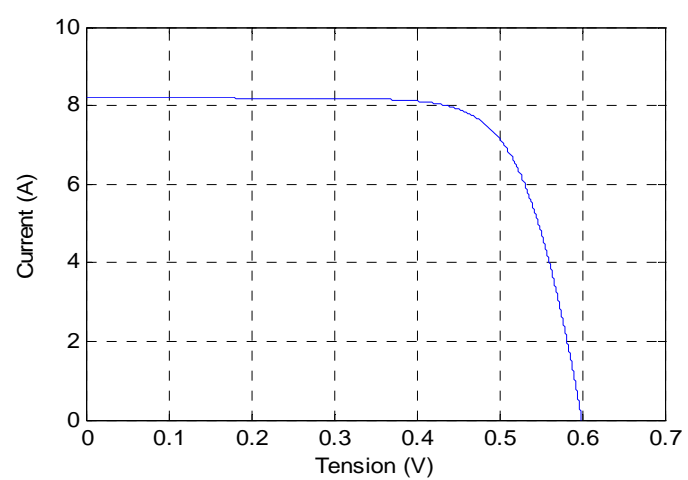

(a)

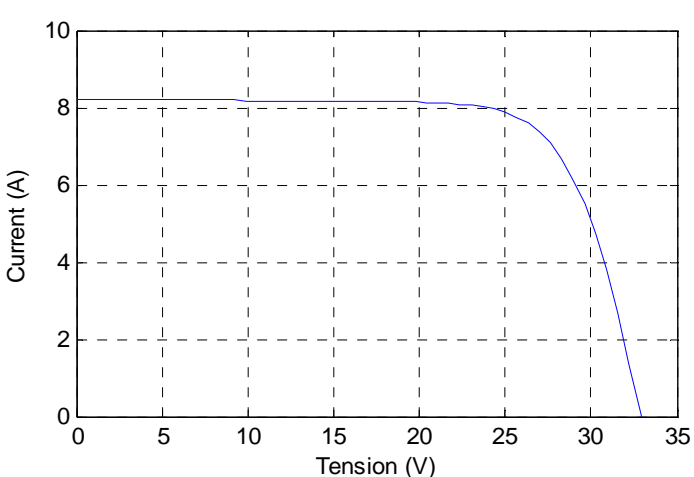

(b)

Fig. 6 I-V characteristics at STC

for one PV cell (a) and for one PV module (b)

As described above, in order to get a higher current and voltage from the PV system, the PV array is formed by connecting PV modules in series and / or in parallel. For the current study, three identical modules are used. Figure 7 shows the connection of the three modules in series and in parallel. 


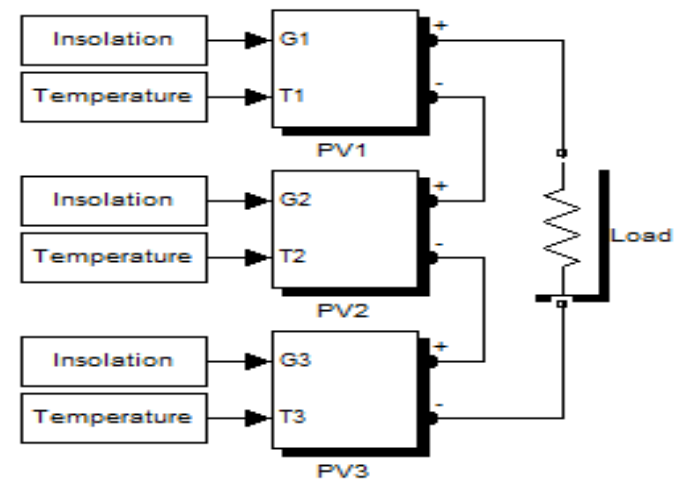

(a)

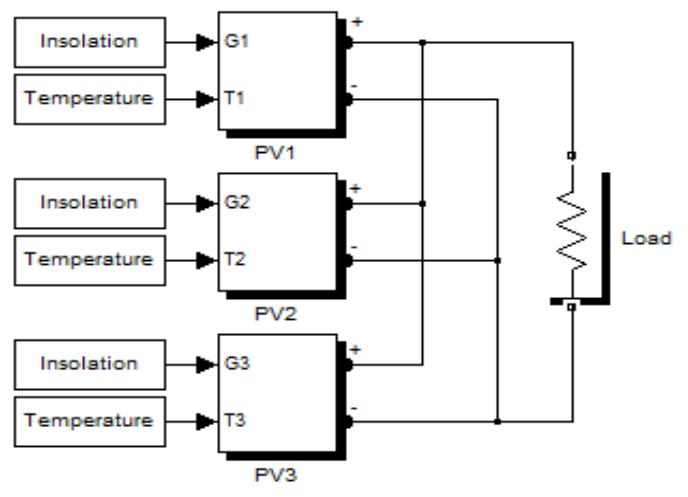

(b)

Fig. 7 Connection of the three modules under study

In series (a) and in parallel (b)

The I-V characteristics of the two modes of connections are presented in Figure 8. The value of the short-circuit current remains the same for one module in the array formed by the 3 seriesconnected modules, and the value of the output voltage of the array depends on the number of the series-connected modules. For this case, and since the modules are similar, the value of the open-circuit voltage of the array is three times more than the value of the open-circuit voltage of one module, as shown in Figure 8 (a). However, for the array formed by connecting the modules in parallel, the open-circuit voltage is equal to the open-circuit voltage of one module, but the short circuit current delivered by the array is three times more than the value of the short circuit current delivered by one module (Figure 8 (b)).

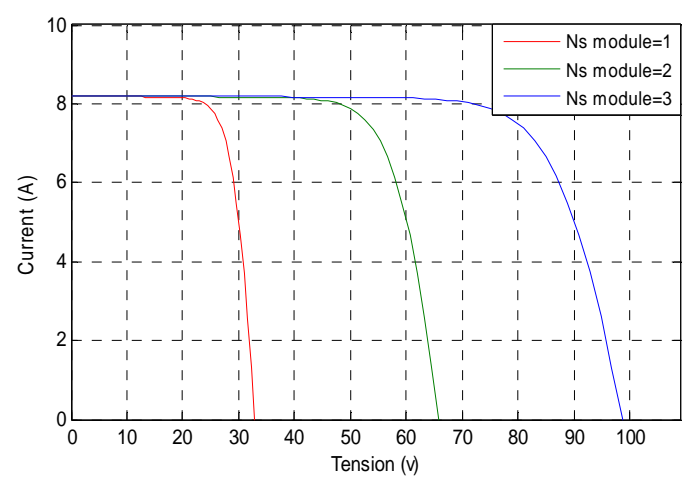

(a)

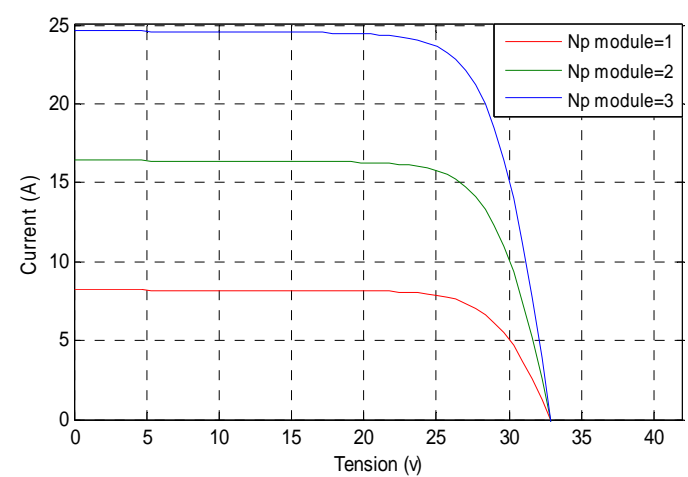

(b)

Fig. 8 I-V diagrams for the two modes of modules connections under uniform irradiation: In series (a) and in parallel (b) 


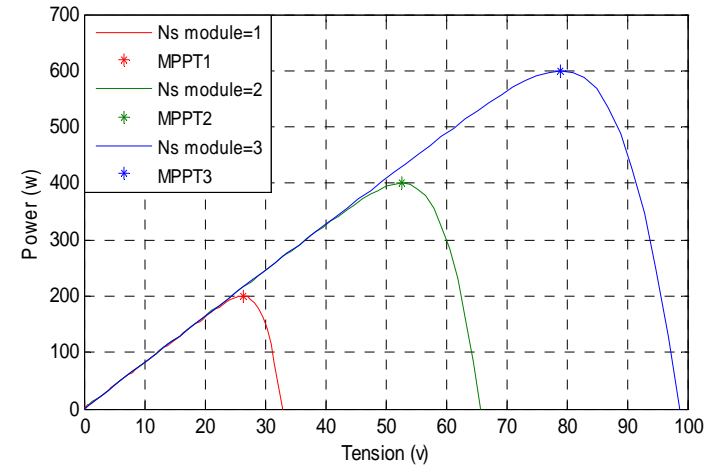

(a)

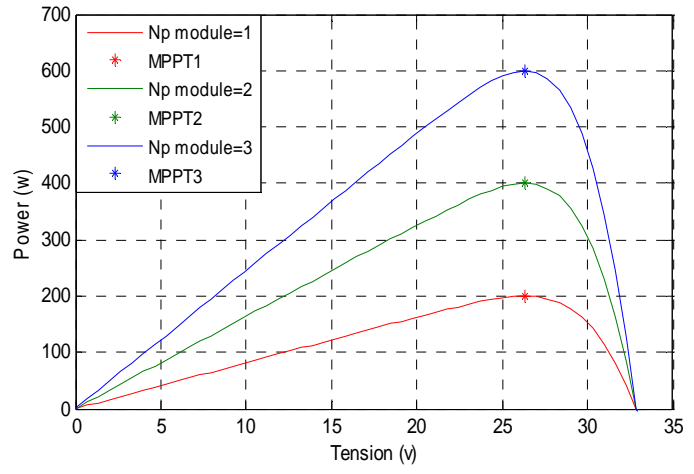

(b)

Fig. 9 P-V curves for the two modes of modules connections under uniform irradiation:

In series (a) and in parallel (b)

The P-V curves of the two cases of the studied arrays discussed above are shown in Figure 9. These curves can be changed as required by connecting the three modules in series to obtain higher voltage or in parallel for higher current. Therefore, for the series connection of the three modules, the power reduction is three times higher than when connected in parallel. In a parallel connection, the power increment is three times higher than when connected in series.

The effect of shading on the electric characteristics of the array composed of three modules, connected in series and then in parallel, is done according to 5 scenarios:

1. Partial shading of $50 \%$ of one module,

2. Total shading of one module,

3. Partial shading of two of three modules at $50 \%$ each,

4. Total shading of two modules,

5. Shading of the three modules, one at $50 \%$, one at $75 \%$, and the last at $100 \%$.

The detailed Simulink model used to study the shading effect for the fourth scenario with parallel-connected modules is depicted in Figure 10. 


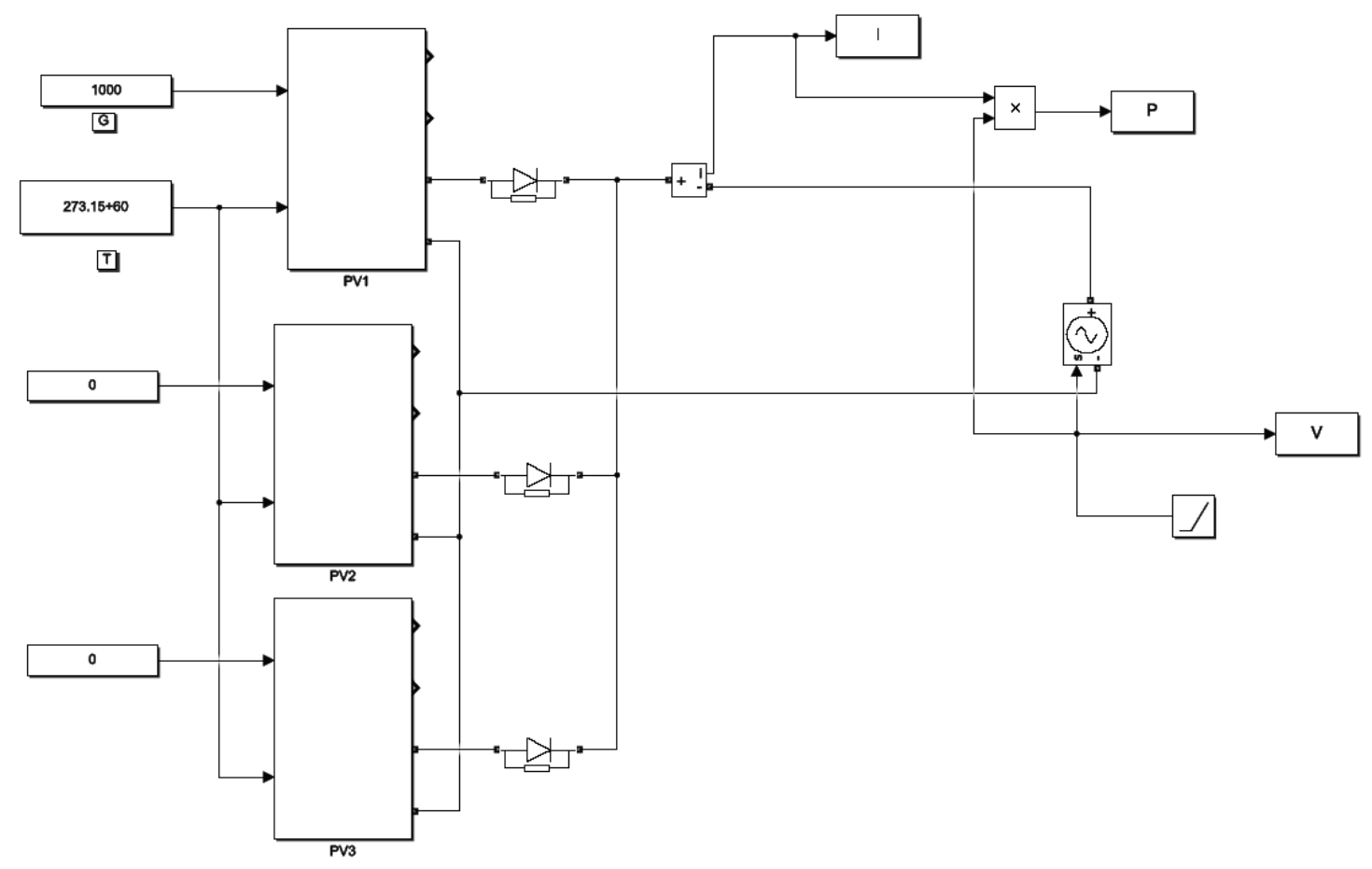

Fig. 10 Matlab/simulink model for scenario 4 with parallel-connected modules

The I-V characteristics of the five scenarios of partial shading of the array compared to the I-V curve of the array at uniform insolation are depicted in Figure 11. The curves of the seriesconnected system (Figure 11 (a)) can be divided into two groups: the first one contains curves similar to that of the non-shaded system and is characterized by the absence of the bypass diodes, while the second group of curves exhibits multiple stairs due to non-uniformity of the irradiation with the implementation of bypass diodes that prevent current limiting at particular operating points and increase the available power. The number of stairs is equal to the number of patterns. In the partial shading scenarios, the values of the short circuit current for the series-connected system are equal and have the same value as the non-shaded system, since the current flowing across them is the same, except for the scenario $\mathrm{N}^{\circ} 5$ where the short circuit current drops to the half, because of the higher ratio of the shaded area $(75 \%$ of the total area). The open-circuit voltage for the series-connected case is multiplied but closely related to the presence of the bypass diode. However, scenario $\mathrm{N}^{\circ} 5$ remains an exception that should be noted, since the value of the open-circuit voltage drops dramatically despite the presence of the effect of the bypass diode (reflected by the shape of the curve), probably due to the high ratio of the shaded surface.

For the parallel connection of the modules, the I-V characteristics are presented in Figure 11 (b). The short circuit current is in close relation with the shaded area. However, the open-circuit voltage has the same value for all cases but decreases slightly for the last scenario $\left(\mathrm{N}^{\circ} 5\right)$. 


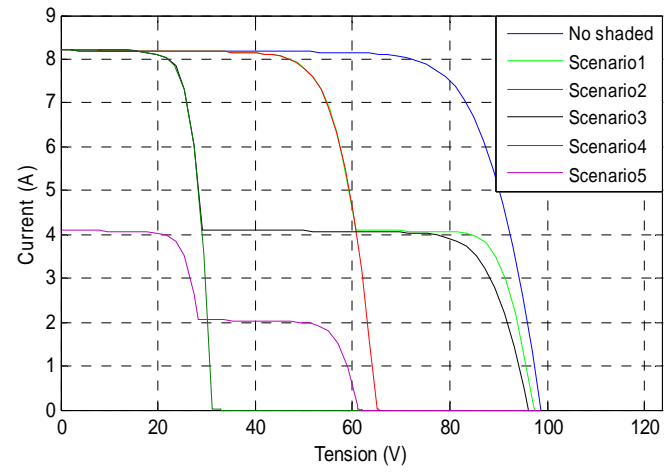

(a)

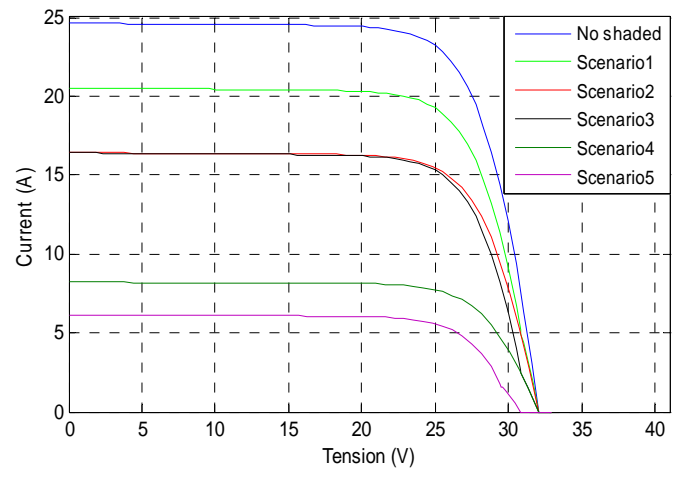

(b)

Fig. 11 I-V characteristics of the 5 scenarios of partial shading:

In series (a) and in parallel (b)

The resulting P-V curves are shown in Figure 12. The peak power is dependent on the connection configuration of the modules. The number of peaks is equal to the number of shading patterns for series-connected modules, as shown in Figure 12(a). Figure 12(b) shows that the partial shading of the modules affects the peak power value but does not affect the shape of the P-V curves.

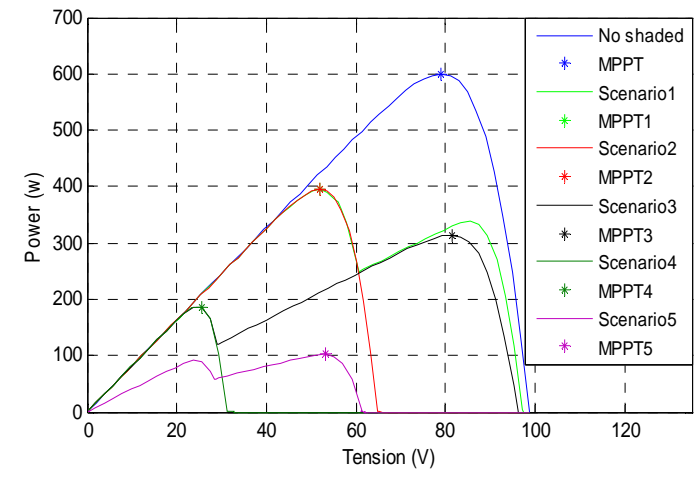

(a)

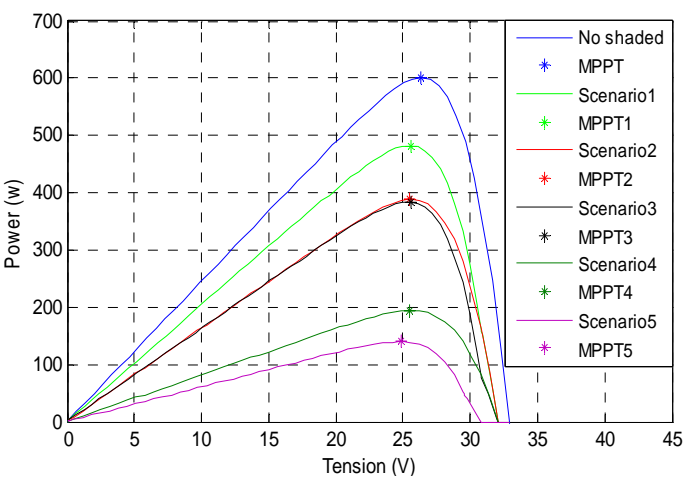

(b)

Fig. 12 I-V characteristics of the 5 scenarios of partial shading:

In series (a) and in parallel (b)

The simulation results lead to the conclusion that it is necessary to connect the modules in a hybrid solution (series/parallel) using bypass diodes to avoid the assumption of the impact of partial shading.

\section{CONCLUSIONS}

The performance of a PV module is highly dependent on various operating conditions. Insolation is considered the most important factor. In this article, the influence of the partial shading effect is studied and analysed with Matlab / Simulink software. Different scenarios for 
the two modes of connection of the modules are considered. From the obtained results, it is concluded that the shading effect results in the degradation of the P-V / I-V characteristics. Implementing bypass diodes and mixing series and parallel connections may increase the available power.

In perspective, future works can be directed to experimentally validate the effect of partial shading on the electrical characteristics of an array, taking into account the exergy analysis. The reconfiguration of PV panels can be taken into consideration to avoid the impact of the partial shading effect in the future.

\section{REFERENCES}

[1] A. Shahsavari, M. Akbari, Potential of solar energy in developing countries for reducing energy-related emissions, Renewable and Sustainable Energy Reviews, Vol. 90, pp. 275291, 2018. https://doi.org/10.1016/j.rser.2018.03.065

[2] T. Sebbagh, R. Kelaiaia, A. Kerboua, A. Metatla, A. Zaatri, Effect of Environmental Conditions and Training Algorithms on the Efficiency of a NARX Based Approach to Predict PV Panel Power Output, International Journal for Engineering Modelling, Vol. 33, No. 3-4, Regular Issue, pp. 27-44, 2020.

\section{https://doi.org/10.31534/engmod.2020.3-4.ri.02f}

[3] S. Lalouni, D. Rekioua, T. Rekioua, E. Matagne, Fuzzy logic control of stand-alone photovoltaic system with battery storage, Journal of power Sources, Vol. 193, No. 2, pp. 899-907, 2009. https://doi.org/10.1016/j.jpowsour.2009.04.016

[4] Q. Zhang, Q. Liang, D.K. Nandakumar, S.K. Ravi, H. Qu, L. Suresh, X. Zhang, Y. Zhang, L. Yang, A. Wee, S. Thye, S.C. Tan, Energy harvesting from shadow-effect, Energy \& Environmental Science, Vol. 13, No. 8, pp. 2404-2413, 2020.

http://dx.doi.org/10.1039/D0EE00825G

[5] H. Patel, V. Agarwal, MATLAB-based modeling to study the effects of partial shading on PV array characteristics, IEEE transactions on energy conversion, Vol. 23, No. 1, pp. 302310, 2008. https://doi.org/10.1109/TEC.2007.914308

[6] P. Sathyanarayana, R. Ballal, P.L. Sagar, G. Kumar, Effect of shading on the performance of solar PV panel, Energy and Power, Vol. 5, No. 1A, pp. 1-4, 2015.

[7] A. Malara, C. Marino, A. Nucara, M. Pietrafesa, F. Scopelliti, G. Streva, Energetic and economic analysis of shading effects on PV panels energy production, International Journal of Heat and Technology, Vol. 34, No. 3, pp. 465-472, 2016.

https://doi.org/10.18280/ijht.340316

[8] T. Sebbagh, R. Kelaiaia, A. Zaatri, An experimental validation of the effect of partial shade on the I-V characteristic of PV panel, Int. J. Adv. Manuf. Technol., Vol. 96, pp.4165-4172, 2018. https://doi.org/10.1007/s00170-018-1858-4

[9] A. Djalab, N. Bessous, M.M. Rezaoui, I. Merzouk, Study of the Effects of Partial Shading on PV Array, In 2018 International Conference on Communications and Electrical Engineering (ICCEE), IEEE, 2018. https://doi.org/10.1109/CCEE.2018.8634512

[10] P. Yadav, A. Kumar, A. Gupta, R.K. Pachauri, Y.K. Chauhan, V.K. Yadav, Investigations on the effects of partial shading and dust accumulation on PV module performance. In 
Proceeding of International Conference on Intelligent Communication, Control and Devices, Springer, Singapore, 2017.

https://doi.org/10.1007/978-981-10-1708-7 118

[11] J.P.N. Torres, S.K. Nashih, C.A. Fernandes, J.C. Leite, The effect of shading on photovoltaic solar panels, Energy Systems, Vol. 9, No. 1, pp. 195-208, 2018.

https://doi.org/10.1007/s12667-016-0225-5

[12] S. Gallardo-Saavedra, B. Karlsson, Simulation, validation and analysis of shading effects on a PV system, Solar Energy, Vol. 170, pp. 828-839, 2018.

https://doi.org/10.1016/j.solener.2018.06.035

[13] R. Ahmad, A.F. Murtaza, H.A. Sher, U.T. Shami, S. Olalekan, An analytical approach to study partial shading effects on PV array supported by literature, Renewable and Sustainable Energy Reviews, Vol. 74, pp. 721-732, 2017.

https://doi.org/10.1016/j.rser.2017.02.078

[14] J. Appelbaum, J. Bany, Shadow effect of adjacent solar collectors in large scale systems, Solar Energy, Vol. 23, No. 6, pp. 497-507, 1979.

https://doi.org/10.1016/0038-092X(79)90073-2

[15] J.-W. Bishop, Computer simulation of the effects of electrical mismatches in photovoltaic cell interconnection circuits, Solar Cells, Vol. 25, No. 1, pp. 3-89, 1988.

https://doi.org/10.1016/0379-6787(88)90059-2

[16] A. Labouret, M. Villoz, Solar photovoltaic energy, Vol. 9, IET, 2010. https://doi.org/10.1049/PBRN009E

[17] K. Ishaque, Z. Salam, A. Shamsudin, M. Amjad, A direct control based maximum power point tracking method for photovoltaic system under partial shading conditions using particle swarm optimization algorithm, Applied Energy, Vol. 99, pp. 414-422, 2012.

https://doi.org/10.1016/i.apenergy.2012.05.026

[18] https://www.energymatters.com.au/images/kyocera/KC200GT.pdf (Checked on December $13^{\text {th }}, 2020$ ) 